Editorial:

\title{
Re-examining cognitive tools: New developments, new perspectives, and new opportunities for educational technology research
}

\author{
Christopher Drew \\ Swinburne Online University
}

\begin{abstract}
The concept of educational technologies as cognitive tools or mindtools emphasises the importance of learning with not from technology. When cognitive tools are designed with student-led learning in mind, they ideally help to extend and scaffold learners' higher-order cognition both when the technology is in use and long after the cognitive partnership has ended. With new wearable, immersive and increasingly personalised educational technologies emerging, this collection of articles reflects upon the value and applicability of the cognitive tools concept in 2019. It works to progress unsettled debates on the definition, design and use of the cognitive tools in light of technological change and highlights the continued relevance of the concept moving forward.
\end{abstract}

\section{Introduction}

The idea of digital technologies as "cognitive tools" or "mindtools" has its roots in social constructivist psychology. Social constructivists such as Vygotsky emphasise the role of cultural tools in supporting the development of mental functioning. When applied to educational technologies, this school of thought led to the rise of the notion of educational technologies as cognitive tools that work as partners in learning. Notably, Pea highlighted in 1985 the difference between using technology to achieve efficiency in achieving a task and using technology to reorganise mental schemata. For Pea, educational technologies become cognitive tools when they not only make tasks easier to achieve, but also support learners to organise and reorganise their thoughts.

Later, Salomon (1993) progressed the research on cognitive tools by differentiating between effects with technology and effects of technology. With an interest in distributed cognition through intellectual partnerships between learners and educational technologies, Salomon's scholarship challenges us to focus on how education technologies can support human cognition rather than simply augment it. Salomon, Perkins, and Globerson (1991 p. 5) aptly explain that a cognitive tool:

\begin{abstract}
allows mindful learners to engage in cognitive processes that are of a higher order than the ones they would display without that partnership. The individual's performance is still assessed, but under conditions that allow them to stretch their cognitive muscles to the maximum.
\end{abstract}

In the quote above, Salomon et al. (1991) present the effects with cognitive tools: namely, that they can help learners to perform at higher levels of cognition than if the tool were unavailable.

However, Salomon and colleagues (1991) also expand on this hypothesis by indicating that cognitive tools should also have significant positive residual impacts on human cognition. Here, they hark back to the scholarship of Bruner on scaffolding and Vygotsky on the zone of proximal development to make the case for learning environments in which technologies cultivate skills and cognitive abilities that can live on beyond the technological intervention. These residual benefits are what they call the effects of technology. They make much of the fact that effects of technology should be a core goal of educators because the kinds of cognitive capacities "one would want to cultivate in school [...] are not necessarily context-bound" (p. 6). In other words, cognitive tools should support not only distributed cognition, but also independent cognitive development. 
By the mid-1990s, Jonassen and colleagues became the principal proponents of the cognitive tools concept. During this era, it became increasingly evident that cognitive tools would be quite normal in the schools, universities and workplaces of the future. Thus, Jonassen and his colleagues were more concerned with progressing literature on effects with educational technologies (Jonassen, 1995, 2000, 2011; Jonassen \& Reeves, 1996). Jonassen's highly influential scholarship into cognitive tools - which he and his colleagues later increasingly labelled mindtools - highlighted the idea of using cognitive tools in student-led learning scenarios wherein "learners function as designers" (Jonassen, Carr, \& Yueh, 1998, p. 28), using cognitive tools to effectively model, organise, visualise and interpret their knowledge.

\section{Cognitive tools today}

Today, the concept of cognitive tools continues to offer a relevant and important lens through which we can understand how learners can leverage the capabilities and affordances of contemporary technologies to learn (Herrington \& Parker, 2013; Hwang, Shi, \& Chu, 2011; Liu, Horton, Toprac, \& Yuen, 2011; Wang, Hsu, Reeves, \& Coster, 2014; Zap \& Code, 2016). However, following Iiyoshi, Hannafin, and Wang (2005, p. 291), it remains the case that "cognitive tool technology offers substantial potential to improve learning, but requires significant study to determine the factors that influence their successful application" (see also B. Kim \& Reeves, 2007; M. C. Kim, 2012).

Furthermore, over the course of the intervening decades since the cognitive tools concept was first popularised, the educational technology landscape has transformed drastically from one in which desktop computer-assisted learning packages and static hypermedia environments were considered state of the art, into one where technologies are becoming increasingly personalised and integrated into everyday life. Internet-connected mobile, wearable, and embedded computing devices proliferate; and students and teachers routinely use online social media for personal as well as educational purposes. Educational technologies are increasingly able to detect and react to humans' physical, emotional and motivational changes (Bower \& Sturman, 2015). With these technological advancements, the cognitive tools concept needs to be re-examined to ascertain how it can be both applied and adapted for emerging technologies as we move forward.

With all of the above in mind, this special issue has brought together a timely discussion of cognitive tools for learning in post-secondary education. The four articles in this issue revisit the concept of cognitive tools in light of recent developments and advances not only technologically, but also with respect to learning theory, pedagogy, instructional design, cognitive science, and psychology.

\section{The articles in this issue}

Despite its influence over several decades, the cognitive tool concept is surprisingly difficult to define. It opens itself up to various interpretations as scholars attempt to apply the term to their own research and the technologies. While the difficulty we face in pinning down a single definition of cognitive or mindtools highlights the versatility of the cognitive tool concept across a range of contexts, this difficulty also makes attempts to progress sustained, critical inquiry into the concept more complex. Indeed, as Pakdaman-Savoji, Nesbit, and Gajdamaschko aptly indicate in the first article of this issue, it is appropriate to question "whether its divergent meanings retain a common or core sense that offers value in the field of educational technology and learning design" (p. 1) as we move into the coming decades.

To this end, several of the articles in this issue work to stimulate scholarly discourse on future definitional directions for the cognitive tools concept. Indeed, the first article in this issue opens with what appears to be a central problem within the cognitive tools literature: "We found the term cognitive tool was often used vaguely or with extreme generality" (p. 1). Aiming to address this issue, the authors' systematic literature review presents what they see as common attributes of cognitive tools across the literature: representation, interactivity, and distributed cognition. They argue that these three definitional categories can help future educational technology designers to more effectively design their tools in ways that support learners' cognition; while also helping scholars to more effectively clarify how the tools in their research act as cognitive partners in learning. 
Similarly, in the second article in this issue, Tan uses cultural historical activity theory (CHAT) to explore the nuanced differences between how we conceptualise cognitive tools, mindtools, and social mindtools. Using CHAT, this article follows the likes of Solomon et al. (1991) in highlighting the differential distribution of cognitive load between machines and people (and among people), which has benefits for identifying the trajectory of cognitive tool analysis. Namely, Tan maps the progression of these terms through the 1990s to now, arguing that the progression of the cognitive tools concept has paralleled the emergence of new tools. Tan's article leaves the reader with a clarified understanding of the various ways cognitive tools can be conceived, created and applied. The article then feedsforward to the potential of new cognitive tools that not only embrace the overlap between the social and cognitive domains of learning, but that are also designed with the intersection of emotional states of learning and higher-order cognition in mind.

Leading from Tan's article is an analysis of potential future directions for cognitive tool research from Ge, Turk, and Hung. These scholars identify several contemporary technologies such as social networking sites, blogs and smartphone apps and examine them as tools that support higher-order cognition. They then employ self-determination theory to identify how cognitive tools can also have important motivational functions that support learning. They concur with Tan that future avenues for cognitive tools literature necessarily need to explore how emergent cognitive tools can also act as motivational and emotional partners that can underpin higher-order thinking. They highlight that there is fertile ground for future studies that examine how cognitive tools not only support domain-specific and domain-generic cognition, but could also help learners to extend their autonomy, competence and relatedness while learning.

The final article in this issue grapples with how cognitive tools can be used in the context of growing pressures placed on higher education institutions to promote "workforce readiness" (O'Neil \& O'Neil, 2014); namely, the highlight that there has been a push towards project-based learning which might help ease students into workforce-like learning scenarios (Jollands, Jolly, \& Molyneaux, 2012). In light of this, Peng, Wang, Sampson, and van Merriënboer explore the role of cognitive tools for supporting students placed in workforce-like project-based learning situations. They present a visualisation-based cognitive tool that is embedded within a complex project-based scenario. Their article then explores how the visualisation-based cognitive tool might act as a cognitive partner to support students' learning. Their findings highlight the potential for cognitive tools to support learning in workplace-like project-based learning environments. This article opens an interesting dialogue about the role of cognitive tools in the context of a global push towards project-based learning and workforce readiness in higher education. In particular, the cognitive tool in their study was found to be very useful for both scaffolding simple-tocomplex tasks and enabling students to articulate their learning and development in a project-based context.

\section{The future of cognitive tools}

Considered together, the articles in this issue raise several key thought-provoking issues that scholars interested in the intersection of technologies and cognitive theories should look out for in coming years. There are two key insights that unite the scholarship in this special issue. Firstly, the conceptualisation of cognitive tools or mindtools may be evolving with technological change. It was very interesting to compare how the first two articles in this issue grappled with definitional confusion over the very concept of cognitive tool in their own unique ways. Debate over what constitutes a cognitive tool has very real impacts on how educational technologists design and use cognitive tools for student learning, and this debate will not be settled in just one journal issue.

The second key insight that emerges clearly through this special issue is the growing emphasis scholars of educational technology are placing on the intersection of the cognitive domain of learning with social, emotional and motivational domains. As Ge, Turk, and Hung argue in the third article in this issue, this may be due to the growing capacity for educational technologies to support emotional and motivational learning. In light of this trend, I look forward to research in coming decades that explores how educational technologies that support motivational and emotional domains of learning might also help to underpin students' sustained higher-order cognition. 


\section{Acknowledgements}

I am grateful to Mark J. W. Lee who I relied on heavily for advice, mentorship and collegiality throughout 2018. I would also like to acknowledge the reviewers and authors for all articles submitted for this issue who put in countless hours of intellectual labour. Lastly, thank you to the editors and copyeditors of AJET who have been encouraging and supportive throughout the process of developing this issue.

\section{References}

Bower, M., \& Sturman, D. (2015). What are the educational affordances of wearable technologies? Computers \& Education, 88, 343-353. https://doi.org/10.1016/j.compedu.2015.07.013

Herrington, J., \& Parker, J. (2013). Emerging technologies as cognitive tools for authentic learning. British Journal of Educational Technology, 44(4), 607-615. https://doi.org/10.1111/bjet.12048

Hwang, G.-J., Shi, Y.-R., \& Chu, H.-C. (2011). A concept map approach to developing collaborative mindtools for context-aware ubiquitous learning. British Journal of Educational Technology, 42(5), 778-789. https://doi.org/10.1111/j.1467-8535.2010.01102.x

Iiyoshi, T., Hannafin, M. J., \& Wang, F. (2005). Cognitive tools and student-centred learning: Rethinking tools, functions and applications. Educational Media International, 42(4), 281-296. https://doi.org/10.1080/09523980500161346

Jollands, M., Jolly, L., \& Molyneaux, T. (2012). Project-based learning as a contributing factor to graduates' work readiness. European Journal of Engineering Education, 37(2), 143-154. https://doi.org/10.1080/03043797.2012.665848

Jonassen, D. H. (1995). Computers as cognitive tools: Learning with technology, not from technology. Journal of Computing in Higher Education, 6(2), 40-73. https://doi.org/10.1007/BF02941038

Jonassen, D. H. (2000). Computers as mindtools for schools: Engaging critical thinking. Englewood Cliffs, NJ: Prentice Hall.

Jonassen, D. H. (2011). Supporting problem solving in PBL. Interdisciplinary Journal of Problem-Based Learning, 5(2), 95-112. https://doi.org/10.7771/1541-5015.1256

Jonassen, D. H., \& Reeves, T. C. (1996). Learning with technology: Using computers as cognitive tools. In D H. Jonassen (Ed.), Handbook of research for educational communications and technology (pp. 693-719). New York, NY: Simon \& Schuster Macmillan.

Jonassen, D. H., Carr, C., \& Yueh, H. P. (1998). Computers as mindtools for engaging learners in critical thinking. TechTrends, 43(2), 24-32. https://doi.org/10.1007/BF02818172

Kim, B., \& Reeves, T. C. (2007). Reframing research on learning with technology: In search of the meaning of cognitive tools. Instructional Science, 35(3), 207-256. https://doi.org/10.1007/s11251006-9005-2

Kim, M. C. (2012). Revisiting cognitive tools: Shifting the focus to tools-in-use. Educational Technology, 52(4), 14-24. Retrieved from https://www.jstor.org/stable/44430054

Liu, M., Horton, L., Toprac, P., \& Yuen, T. T. (2011). Examining the design of media rich cognitive tools as scaffolds in a multimedia problem-based learning environment. In M. Orey, S. A. Jones, \& R. M. Branch (Eds.), Educational media and technology yearbook (Vol. 36, pp. 113-125). New York, NY: Springer. https://doi.org/10.1007/978-1-4614-1305-9 10

O’Neil, H. F., \& O’Neil, H. F. (2014). Workforce readiness: Competencies and assessment. New York, NY: Psychology Press.

Pea, R. D. (1985). Beyond amplification: Using the computer to reorganize mental functioning. Educational Psychologist, 20(4), 167-182. https://doi.org/10.1207/s15326985ep2004_2

Salomon, G. (1993). On the nature of pedagogic computer tools: The case of the writing partner. In S. P. Lajoie \& S. J. Derry (Eds.), Computers as cognitive tools (pp. 179-196). Hillsdale, NJ: Erlbaum.

Salomon, G., Perkins, D. N., \& Globerson, T. (1991). Partners in cognition: Extending human intelligence with intelligent technologies. Educational Researcher, 20(3), 2-9. https://doi.org/10.3102\%2F0013189X020003002

Wang, S.-K., Hsu, H.-Y., Reeves, T. C., \& Coster, D. C. (2014). Professional development to enhance teachers' practices in using information and communication technologies (ICTs) as cognitive tools: Lessons learned from a design-based research study. Computers \& Education, 79(1), 101-115. https://doi.org/10.1016/j.compedu.2014.07.006 
Zap, N., \& Code, J. (2016). Virtual and augmented reality as cognitive tools for learning. In G. Veletsianos (Ed.), Proceedings of EdMedia 2016: World Conference on Educational Media and Technology (pp. 1340-1347). Waynesville, NC: AACE. Retrieved from https://www.learntechlib.org/p/173128/

Corresponding author: Christopher Drew, cdrew@swin.edu.au

Please cite as: Drew, C. (2019). Editorial: Re-examining cognitive tools: New developments, new perspectives, and new opportunities for educational technology research. Australasian Journal of Educational Technology, 35(2), i-v. https://doi.org/10.14742/ajet.5389 